\title{
Behavior and design of HSC members subjected to flexure
}

\author{
C. Magureanu, B. Heghes \& D. Moldovan \\ Department of Technical University of Cluj-Napoca, Romania
}

\begin{abstract}
This paper presents an overview of the research on the flexural behavior of HSC members. The study has resulted in the identification of factors that affect the flexural behavior and design of reinforced concrete members made of HSC. The paper also identifies relevant design issues to extend the current concrete compressive strength limit of about $85 \mathrm{MPa}$ in the Romanian code and EC2 design specification
\end{abstract}

Keywords: beam, flexural members, high strength concrete.

\section{Introduction}

Revolutionary evolutions related to novel materials of construction and modifications and improvements in the behavior of traditional materials have taken place in recent decades. The $21^{\text {st }}$ century definitively will be the millennium of high performance and high strength concrete because the application of the strength concrete in the design of various engineering structures is being constantly increased in different parts of the world.

High-strength concrete is a brittle material and its brittleness increases proportionally with an increase of its strength. It is necessary to provide a greater ductility of elements of HSC in order to apply them in seismic prone areas.

The study report in this paper mainly investigates the implications of using HSC in reinforced concrete flexural members.

\section{Experimental program}

The experimental program contained a number of twelve simple reinforced concrete beams, tested at bending. The beams were realized with concrete with a mean compressive strength of $85 \mathrm{MPa}$, with a constant length of $\mathrm{L}=3200 \mathrm{~mm}$ and 
a section of $125 \times 250 \mathrm{~mm}$. The longitudinal percentage of reinforcement was between $2.033 \%$ to $3.781 \%$ and the transversal reinforcement was the same for all beams, with stirrups $\varnothing 6 / 300 \mathrm{~mm}$.

All the beams were tested with a hydraulic press and loaded with two concentrated loads (see Figure 1). At each increment of the forces, the strain on the multiple heights of the section and the flexural deflection of the beam were recorded. In Table 1 the compressive strength (on the cube with $l=150 \mathrm{~mm}$ ) at the date of testing (at age 100 days) is presented.

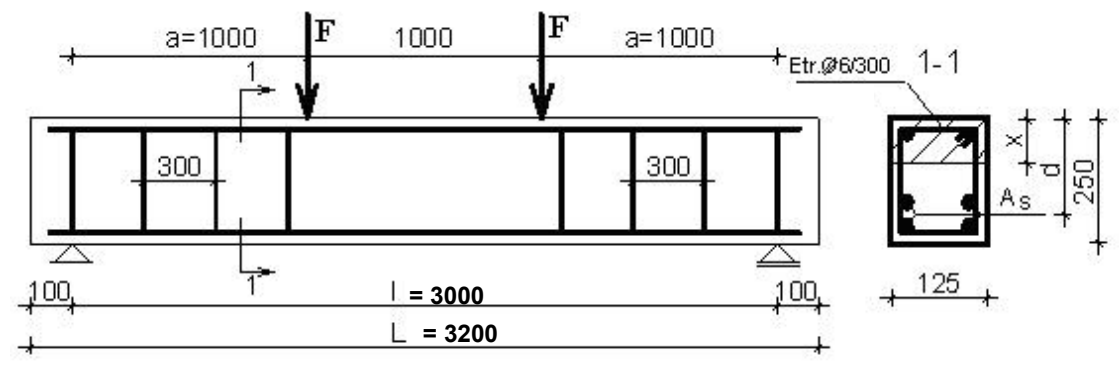

Figure 1: $\quad$ The loading schemes.

Table 1: Compressive strength of concrete and the longitudinal reinforcement percentage.

\begin{tabular}{|l|c|c|}
\hline Beams & $\mathrm{f}_{\mathrm{c}, \text { cube }}[\mathrm{MPa}]$ & $\rho_{l}(\%)$ \\
\hline FT 5.2-1 & 91.0 & 2.033 \\
\hline I 1-1 & 92.4 & 2.621 \\
\hline I 3-1 & 85.0 & 3.357 \\
\hline
\end{tabular}

The longitudinal reinforced reinforcement $\rho_{l}$ was with steel type $\mathrm{B}$ with $\mathrm{f}_{\mathrm{yk}}=355 \mathrm{MPa}$ (PC52), and the stirrups with steel with $\mathrm{f}_{\mathrm{yk}}=255 \mathrm{MPa}$.

\section{Effect of reinforcement}

In order to see the effect of the percentage of steel on the response of the HSC beam, the beam FT5.1-1, I2-1, I4-1 has been considered for analysis with three percent steel reinforcement. Figure 2 presents the effect of steel percentage $\rho_{l}$ on the moment-curvature response of the beams at the centre of the span.

An increase of the ultimate bearing capacity of the beam with $\rho_{l}$ may be observed.

A numerical investigation has also been carried out for the beams to observe the effect of the percentage of steel on the response of various parameters such as load and curvature. Figures 3 and 4 present the variations of these parameters due to the percentage of steel. 
From figures 3 and 4 it is observed that an increase in tension steel increases the ultimate load carrying capacity but decreases the curvature of the section.

The photograph of crushed cover concrete is shown in Figure 5.

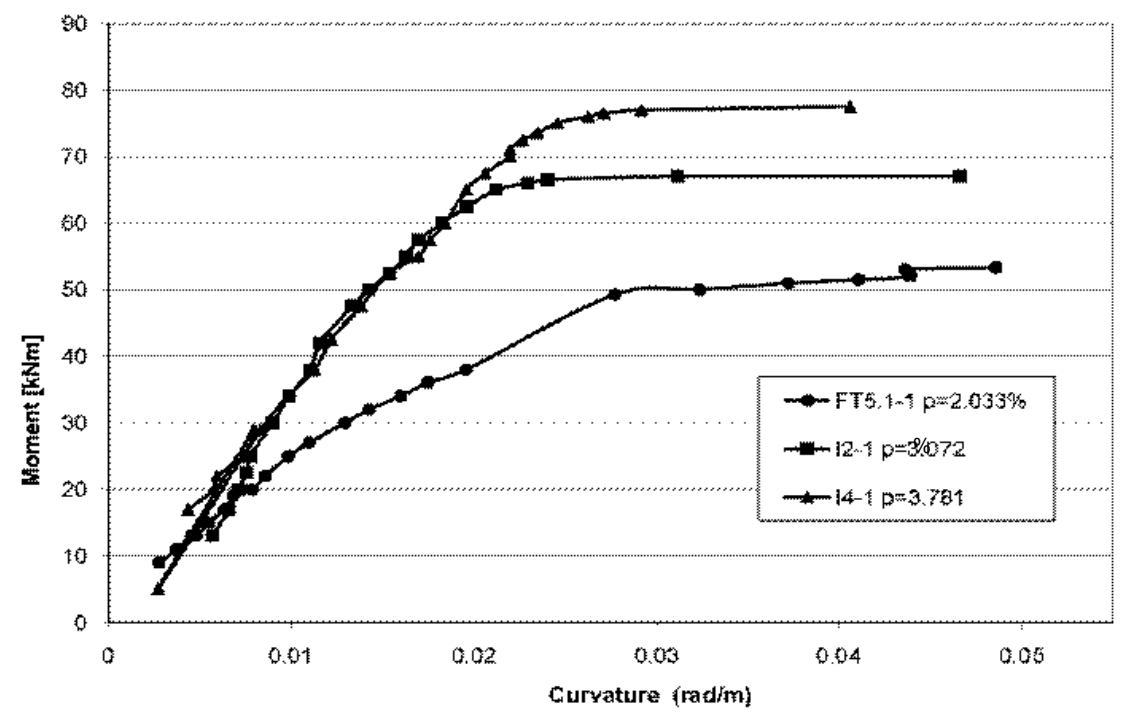

Figure 2: Effect of percentage of steel on the moment-curvature response.

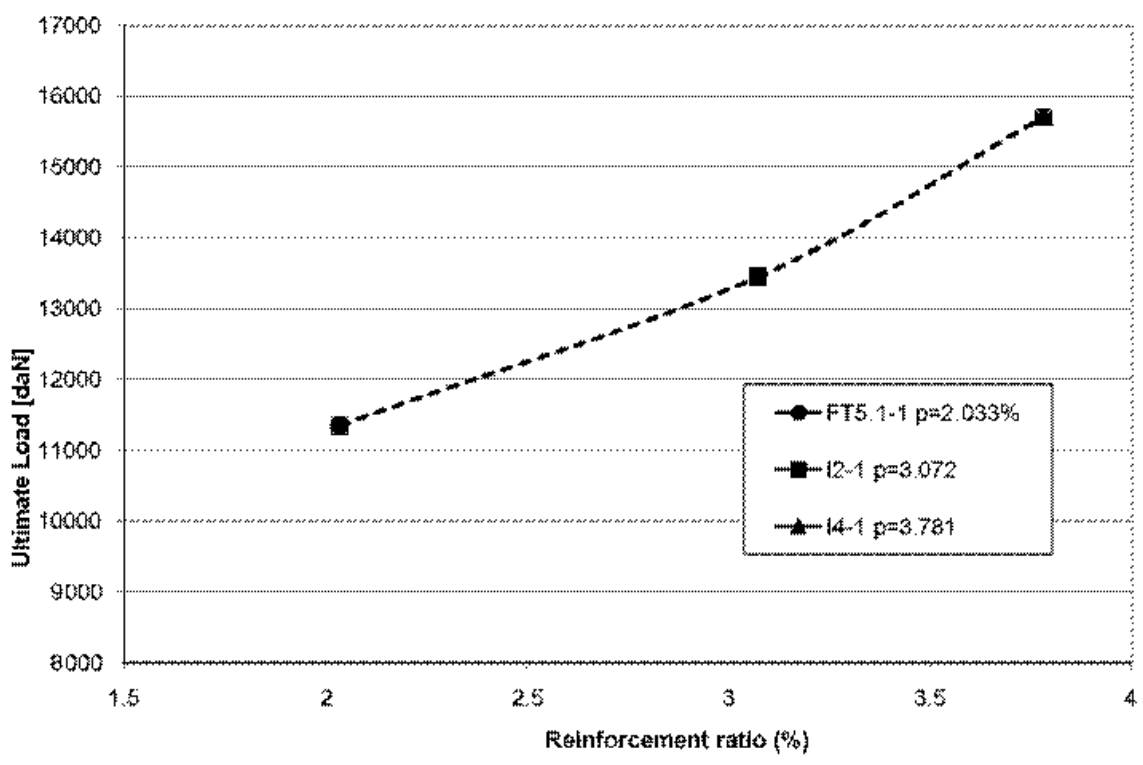

Figure 3: Effect of percentage of steel on load. 
86 High Performance Structures and Materials IV

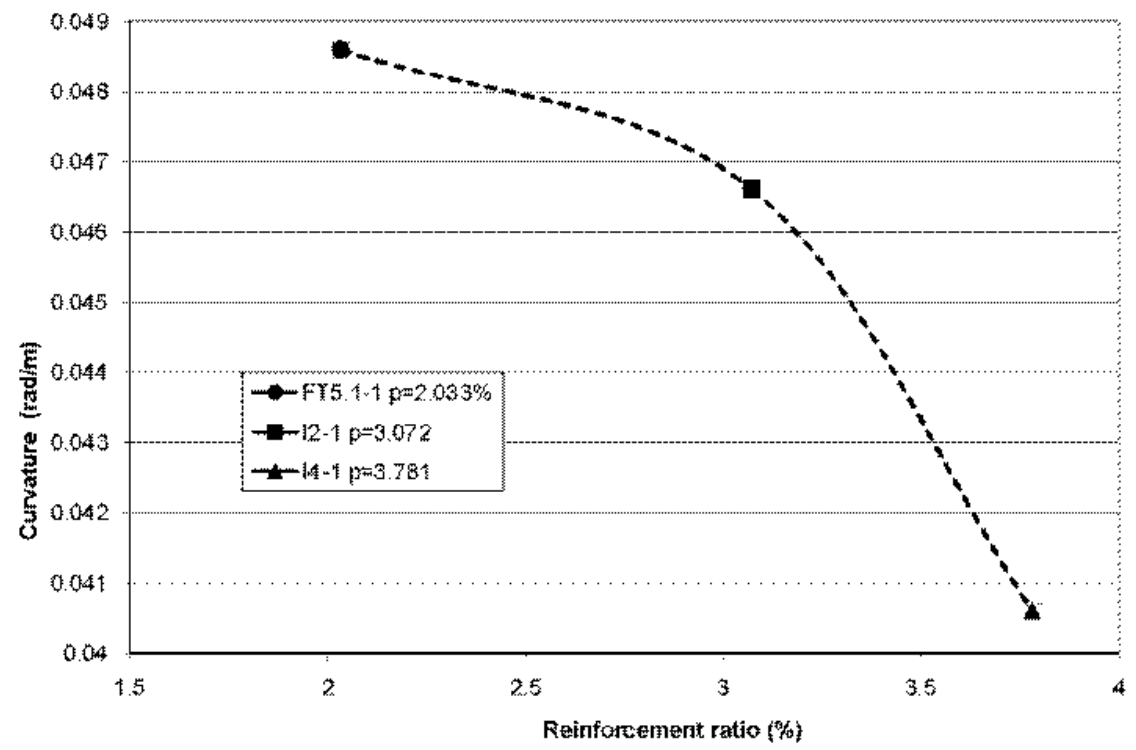

Figure 4: $\quad$ Effect of percentage of steel on curvature.

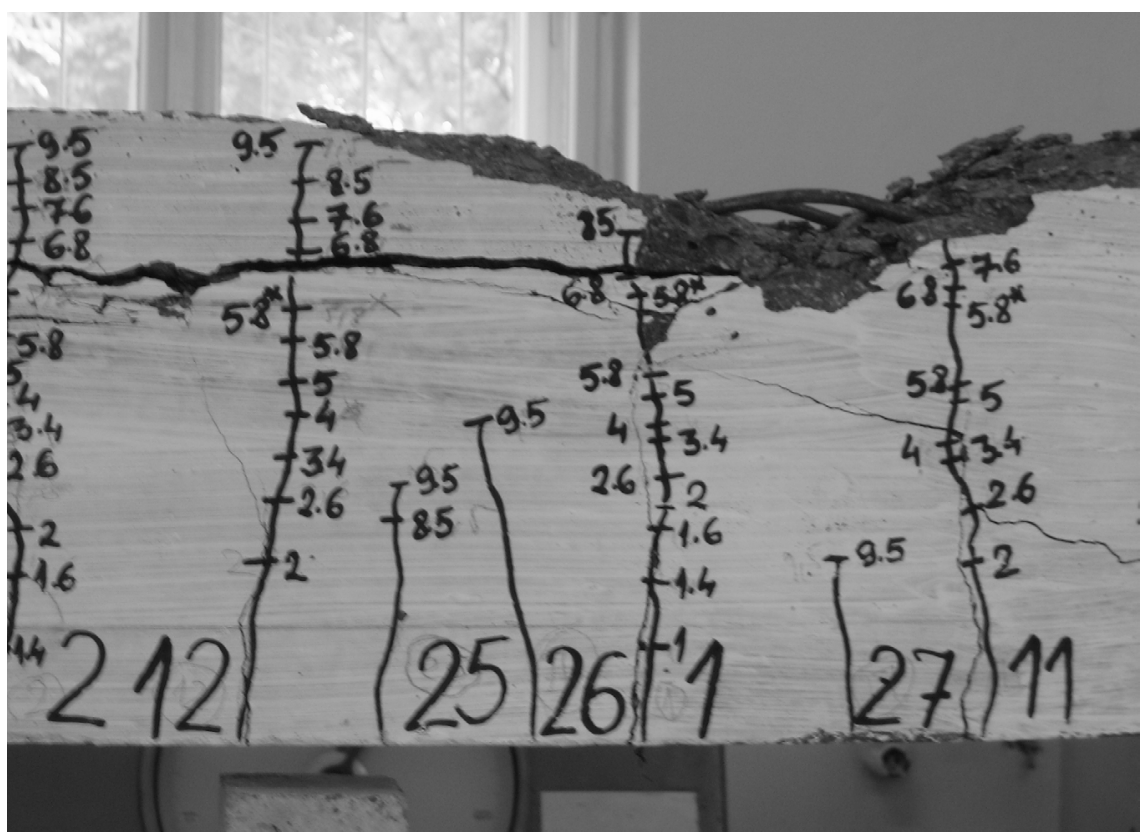

Figure 5: $\quad$ Failure mode. 


\section{Flexural resistance using rectangular stress distribution}

A large number of investigations have been carried out in the past on the flexural behavior of HSC beams, but controversy still remains with regard to some design issues.

An important design issue is the relation moment-curvature or the ability of reinforced HSC beams to deform at or near the ultimate load without significant strength loss.

Design regulations contained in Romanian code (STAS 10107/0-90 [9]) and Eurocode2 ([7,8]: design of concrete structures) has also been examined. The stress-strain curves for concrete in compression obtained from flexural tests are similar to those generated from the monoaxial loaded specimen and give close prediction of the experimental data on the moment-curvature relationship and ultimate moment capacity of the beams. The stress-strain curves used for normal strength concrete are also used to describe the behavior of $\mathrm{HSC}$, but in Eurocode 2 there are differences of values for the coefficients used to define HSC. The theoretical results have been compared with the experimental values for limits on the neutral axis depth, see Table 2, and the ultimate moment of resistance of the section $\mathrm{M}_{\mathrm{u}, \mathrm{e}}$.

The experimental ultimate strength corresponding to the initiation of concrete crushing $\mathrm{M}_{\mathrm{u}, \mathrm{e}}$ was compared with that predicted by the STAS 10107/0-90 [9].

It may be seen that STAS 10107/0-90 and Eurocode2 give a conservative estimate for the ultimate moment capacity of the test beams with a mean of 1.80 for the ratio of experimental-to-predicted values.

Table 2: $\quad$ Prediction of limits on neutral axis depth.

\begin{tabular}{|c|c|c|c|c|c|c|c|}
\hline \multirow{3}{*}{ Beams } & \multirow{3}{*}{$\begin{array}{c}\text { Concrete } \\
\text { strength } \\
{[\mathrm{MPa}]}\end{array}$} & \multirow{3}{*}{$\begin{array}{c}\text { Tensile } \\
\text { reinf. Ratio } \\
\rho_{l}[\%]\end{array}$} & \multicolumn{3}{|c|}{$\mathrm{x}_{\mathrm{u}}(\mathrm{mm})$} & \multirow{2}{*}{$\mathrm{X}_{\mathrm{u}, \mathrm{e}}$} & \multirow{2}{*}{$\mathrm{X}_{\mathrm{u}, \mathrm{e}}$} \\
\hline & & & & STAS & & & \\
\hline & & & Exp. & $\begin{array}{c}10107 / 0- \\
90\end{array}$ & 2004 & $\mathbf{X}_{\mathrm{u}, \mathrm{stas}}$ & $\mathrm{X}_{\mathrm{u}, \mathrm{EC} 2}$ \\
\hline FT 5.1-1 & 85.00 & 2.033 & 26.10 & 30.45 & 41.94 & 0.85 & 0.62 \\
\hline I 2-1 & 85.10 & 3.072 & 34.53 & 41.06 & 57.53 & 0.84 & 0.60 \\
\hline I 4-1 & 89.92 & 3.781 & 40.51 & 48.76 & 69.25 & 0.83 & 0.58 \\
\hline
\end{tabular}

Table 3: $\quad$ Prediction of ultimate moment.

\begin{tabular}{|c|c|c|c|c|c|c|c|}
\hline \multirow[b]{2}{*}{ Beams } & \multirow[b]{2}{*}{$\begin{array}{c}\text { Concrete } \\
\text { strength } \\
\text { [MPa }]\end{array}$} & \multirow[b]{2}{*}{$\begin{array}{c}\text { Tensile } \\
\text { reinf. } \\
\text { ratio } \rho_{l}[\%]\end{array}$} & \multicolumn{3}{|c|}{$\mathrm{M}_{\mathrm{u}}[\mathrm{kNm}]$} & \multirow{2}{*}{$\frac{M_{u, e}}{M_{u, s t a s}}$} & \multirow{2}{*}{$\frac{M_{u, e}}{M_{u, E C 2}}$} \\
\hline & & & Exp. & $\begin{array}{l}\text { STAS } \\
10107 / 0- \\
90\end{array}$ & $\begin{array}{l}\text { EC 2 } \\
2004\end{array}$ & & \\
\hline FT 5.1-1 & 85.00 & 2.033 & 56.75 & 27.04 & 26.84 & 2.09 & 2.11 \\
\hline I $2-1$ & 85.10 & 3.072 & 67.25 & 36.03 & 36.65 & 1.86 & 1.88 \\
\hline I $4-1$ & 89.92 & 3.781 & 78.50 & 43.94 & 43.36 & 1.78 & 1.81 \\
\hline
\end{tabular}




\section{Conclusion}

The objective of this paper is to predict the behavior of flexural resistance and curvature for the beams with HSC.

In case of HSC beams, an increase in the reinforcing steel increases the strength of the members.

The equivalent rectangular stress block specified in STAS 10107/0-90 [9] and Eurocode2 [7,8] for HSC have been found to give conservative predictions for the ultimate moment capacity of HSC beams with concrete strength of about 85 $\mathrm{MPa}$. The research is to be continued.

\section{References}

[1] Magureanu, C., Rosca, B., Heghes, B., Shear and bending strength of highstrength reinforced concrete beams. Keep concrete attractive., vol.1

[2] Proc. of the fib. symposium: Budapest, Hungary, pp.773-778, 1984

[3] Magureanu, C., Heghes, B., Experimental study in ductility reinforced concrete beams using high strength concrete. Proc. of the $2^{\text {nd }}$ International Compress: Naples, Italy, 2006.

[4] Magureanu, C., Popa, A., Shear and bending strength analysis for high strength concrete beams Global Construction - Ultimate Concrete Opportunities: Dundee, Scotland, UK, pp. 603-608, 2005.

[5] Al Amin Siddique, M., Abdur Rouf, Md., Effect of material properties on behaviour of over-reinforced concrete beams, Asian Journal of Civil Engineering (Building and housing), vol.7, pp. 175-204, 2006.

[6] Rashid, M.A., Manzur, M.A., Reinforced high strength concrete beams in flexure, Structural Journal May-June, pp. 462-470, 2005.

[7] Wu, Z., Choi, W., Mirmiran, A., Rizkalla, S., Zia, P., Flexural behaviour and design of high-strength concrete members. Seventh International Symp. on the utilisation of HS/HP Concrete, vol.1, pp. 421-437, 2005.

[8] Eurocode2 - Design of concrete structures. Part 1. General rules and rules for buildings. Final draft 2004.

[9] SR EN 1992-1-1. Design of concrete structures, ASRO, Dec., 2004.

[10] STAS 10107/0-90- Civil and industrial buildings. Design and detailing of concrete, reinforced concrete and prestressed concrete structural members.

[11] Martin, L., Putkiss, J., Concrete design to En 1992, Second Edition, 2006. 